\title{
Analyzing the Past, Rationalizing the Present, and Formulating the Future of Injection Sites
}

Written by Brooke Baker and Celina Lovisotto

Today, Canada is at the heart of the opioid crisis. Between the years of January 2016 and December 2018, approximately 11,500 Canadians died from an opioid overdose (Taha et al., 2019). As a result of these opioid-related deaths, the average Canadian life expectancy failed to rise for the first time in over 40 years (Probst \& Rehm, 2018). In 2021, the opioid crisis continues to be one of Canada's leading Public Health crises. One of the tools utilized by the Canadian government to combat the current opioid crisis is the use of supervised consumption facilities, or more commonly known as safe injection sites (SIS). By definition, "Supervised consumption facilities operate under a Health Canada exemption from prosecution under federal drug laws. Consumption services use a harm-reduction model, which means they strive to decrease the adverse health, social and economic consequences of drug use without requiring abstinence from drug use" (Vancouver Coastal Health, 2020). There are various highly measurable benefits associated with safe injection sites, namely the reduction of drug-related mortality, overdose hospitalizations, and the transmission of diseases such as AIDS. They also provide a magnitude of harm reduction and outreach services such as addiction therapy and treatment, essential medical care, and they aid in the de-stigmatization of drug users. In conclusion, it has been proven that safe injection sites have evolved in providing positive outcomes to vulnerable populations within Canadian society, with continued advancements for future applications.

Drug users face insurmountable detriments to their personal health and wellbeing, partially due to the lack of available services tailored to addicts. Opioids rates among intravenous drug users are approximately eight times higher than that of non-drug users (Urban Health Research Initiative, 2013). In an attempt to combat this statistic, North America's first legal injection site, InSite, opened its doors in September 2003 to Vancouver's Downtown Eastside, where a high volume of frequent drug users historically reside (Vancouver Coastal Health, 2020). Before the installation of InSite, $35 \%$ of a focus group, including 598 intravenous drug users, were repeatedly admitted to emergency care over three 
years for cutaneous infections related to drug use such as osteomyelitis and endocarditis. After InSite opened, only $9 \%$ of the studied population were readmitted to the hospital for injection-related skin infections. In tandem with this, there has been a rapid decline in 911 calls related to overdose, fewer reported cases of HIV, and 88 fewer deaths per 100,000 people per year ( $\mathrm{Ng}$. J et al., 2017). The benefit of preventing HIV infections and opioid-related strain on Vancouver's healthcare system has been calculated to be $\$ 4.02$ saved for every $\$ 1.00$ invested into SIS (Vancouver Coastal Health, 2020). In the past year, 5,111 individuals have utilized the services of North America's safe injection site for a total of 170,731 visits. This evidently demonstrates the necessity and benefit of safe injection sites as a high volume of at-risk individuals who rely on them for essential services, that would otherwise not be available. In 2020, there were approximately 312 visits to the injection room per day, 3,158 medical treatment interventions such as safe sex education and wound care, 1,314 overdose interventions. Since its opening in 2003, zero overdose-related deaths have occurred at Insite (Vancouver Coastal Health, 2020).

Canada has significantly evolved and altered its collective attitude towards supervised injection sites since the first facility Insite opened in 2003 (Vancouver Coastal Health, 2020). Despite the major controversy that arose, recent data has provided clear evidence that states the positive effects of implicating injection sites in vulnerable cities. As noted in a recent article on February 21, 2019, The Candian Model allows for one to analyze the data and statements towards SISs (Gordon, E., 2018). Specifically, there have been over 6,000 responses to overdoses without recording any deaths, which demonstrates significant improvement in providing vulnerable individuals with another day, week, month and years to live. The article also noted that it was less likely for individuals to develop HIV and infections due to the safe and clean environment when performing the injections. Most notably, a critical improvement that proposes the idea of SISs saving lives is due to the "non-judgemental place that accepts people for who they are" (Gordon, E., 2018). Without these centers and harm reduction 
programs, drug users may feel isolated, worthless, and lack a sense of belonging in the world. The emotions that arise are commonly related to the stigma surrounding supervised consumption sites as the negative interactions and judgements from others make these impotent individuals feel belittled. This may result in barriers to seek help, resulting in poor quality of health along with the idea of mistrust and avoidance of marginalized populations (Knaak, S. et al., 2020.). Fortunately, these environments create a community among similar individuals while destigmatizing them and their substance habits by formulating promising approaches. These include the notion of gaining trust from support workers, receiving proper care, undergoing treatment to cease the use of substances, and ultimately building the stamina to face everyday challenges (Knaak, S. et al., 2020.). As previously mentioned, the contentious discussions that arise from societal perspectives create stereotypes that linger around these centers and the individuals who attend. Nonetheless, it is crucial that we educate the public of the importance of harm reduction and accepting people for their true self as you may not know their underlying story.

There are countless socioeconomic factors surrounding society that are most commonly noted through those who consume substances and attend injection sites, based on collected data. The challenges that individuals face allow one to analyze the exponential trends and understand the importance of implementing harm reduction centers to be readily available for the public. In Vancouver, BC, a study was conducted over the time-period of September 2005 to May 2015 that specifically focuses on street-involved youth (JF. Boivin, E.R. et al., 1970). At Risk Youth Study (ARYS) was a program that was intended to note the socioeconomic trends that are affecting youth, their involvement with substances and providing the necessary resources to cease injection drugs among the young generation. The 383 participants aged 14 to 26 may have experienced homelessness, poor education, unstable jobs, incarceration, sex work involvement, drug dealing, illegal income generation activities, and many other unfortunate events (JF. Boivin, E.R. et al., 1970.). This study analyzed the participants' activity with various substances and provided them with the necessary resources to amend their addictions. Through 
gaining a sense of belonging in society, 171 participants ceased their drug use based on the following implications; stable income support, integrating youth into the community, economic and income security, reducing societal barriers and limiting the stigma (JF. Boivin, E.R. et al., 1970.). One may conclude that the underlying purpose of this study was to bring awareness to the commonly misconceived opioid crisis, specifically occurring around youth while implicating positive changes in one's life for future success.

One may reflect on the changes that have evolved from the opioid crisis, relating to greater awareness of injection sites and providing adequate resources to sustain overall health and wellbeing of these individuals. Nonetheless, it is essential to highlight that our world can instantly change, leading to increased health inequities surrounding low-class populations. Specifically, the global pandemic has caused approximately 1,018 opioid related deaths in Ontario between January and March 2020 (Gomes, T., 2020.). The State of Emergency that was declared particularly impacted the Ethno-Cultural and material deprived neighbourhoods in a negative manner due to the lack of regular drug supply, disruptions to care and reduced capacity at harm reduction centers (Gomes, T., 2020.). The COVID-19 outbreak has affected a diverse range of populations worldwide as each individual experiences different challenges that have arisen from this unprecedented time. It is crucial that we are aware of those who are exceedingly impacted by this virus as they have and continue to experience an absence of connections among others, creating greater hardships both physically, mentally and socially. Moving forward, it is essential that we provide the fundamental necessities to all populations to ensure that no one is left behind.

Addiction is a critical issue that can dictate one's future, their success, and overall-well being. If we as a society continue to neglect individuals in need, we will continue to lose them at an exponential rate. Addiction is a healthcare issue that must be addressed in all levels of government, as it impacts the milieu of society on a broad scale. While safe injection sites are a key element in promoting harm 
reduction and decreasing drug related deaths, the benefit of these sites are limited by funding, stigma, and capacity. For example, InSite is limited to assist roughly $4 \%$ of all intravenous drug users in the Downtown Eastside of Vancouver (Pinkerton SD, 2011). Although healthcare operates on a provincial level, all aspects of government must come together in an effort to tackle stigma and advance the work of today's supervised consumption sites. SIS's are paramount in the recovery of individuals struggling with addiction as they do more than save lives, they also promote resilience, the development of relationships, and reintegration. They fight to mitigate the gap between drug users and the rest of society to provide them with the services they need, that wouldn't otherwise be available. Without cooperation, trust, and understanding from the government, very limited progress can be made. Thousands of Canadians rely on harm reduction services every year, however, this type of outreach can not be sustained without the necessary funding to expand capacity. The Canadian government must instill a universal effort to promote the development of safe injection sites in an attempt to reach all Canadians who are struggling with addiction. Safe injection sites are the first step in combating the opioid crisis, and lowering the number of annual drug related deaths to zero. In the name of progress, education and recovery must take precedence and be recognized as a disease that requires space within the sphere of healthcare. Drug users are people too, and without necessary lifesaving services such as safe injection sites, members of our society will continue to silently slip through the cracks. SISs are not the final destination, but rather a platform to kickstart change and societal reform surrounding the issues of drug use and addiction. We as a whole must continue to advocate for the rights of drug users and their access to essential services. The fate of numerous Canadians lies not within the stars but rather the hands of policymakers, activists, and everyday members of society campaigning for change the fate of Canadians lies with people like you. 
Anon, Vancouver Coastal Health. In-site User Statistics. Available at:

http://www.vch.ca/public-health/harm-reduction/supervised-consumption-sites/insite-user-sta

$\underline{\mathrm{ti}}$

stics [Accessed January 8, 2021].

Gomes, T., 2020. Preliminary Patterns in Circumstances Surrounding Opioid-Related Deaths in Ontario during the COVID-19 Pandemic. Available at:

https://odprn.ca/wp-content/uploads/2020/11/Opioid-Death-Infographic FINAL.pdf [Accessed January 6,2021].

Gordon, E., 2018. What's The Evidence That Supervised Drug Injection Sites Save Lives? NPR. Available at:

https://www.npr.org/sections/health-shots/2018/09/07/645609248/whats-the-evidence-that-s upervised-drug-injection-sites-save-lives [Accessed January 8, 2021].

JF. Boivin, E.R. et al., 1970. Socioeconomic factors associated with cessation of injection drug use among street-involved youth. Available at:

https://substanceabusepolicy.biomedcentral.com/articles/10.1186/s13011-017-0136-z

[Accessed January 6, 2021].

Knaak, S. et al., 2020. Stigma and the Opioid Crisis. Available at:

https://www.mentalhealthcommission.ca/sites/default/files/2020-03/Opioid Report mar 2020 eng.pdf [Accessed January 6, 2021].

Marshall BD; Milloy MJ; Wood E; Montaner JS; Kerr T; 2011. Reduction in overdose mortality after the opening of North America's first medically supervised safer injecting facility: a retrospective population-based study. Lancet (London, England). Available at:

https://pubmed.ncbi.nlm.nih.gov/21497898/ [Accessed January 4, 2021].

Ng. J, Sutherland. C, \& Kolber, M.R., 2017. Does evidence support supervised injection sites? Canadian family physician Medecin de famille canadien. Available at:

https://www.ncbi.nlm.nih.gov/pmc/articles/PMC5685449/ [Accessed January 5, 2021].

Pinkerton SD, 2011. How many HIV infections are prevented by Vancouver Canada's supervised injection facility? Int J Drug Policy. https://pubmed.ncbi.nlm.nih.gov/21450450/ [Accessed January 5, 2021].

Probst, C. \& Rehm, J., 2018. Alcohol use, opioid overdose and socioeconomic status in Canada: A threat to life expectancy? Available at: https://www.ncbi.n/m.nih.gov/pmc/articles/PMC6217603/ [Accessed January 8, 2021].

Taha, S., Maloney-Hall, B. \& Buxton, J., 2019. Lessons learned from the opioid crisis across the pillars of the Canadian drugs and substances strategy. Substance Abuse Treatment, Prevention, and Policy, 14(1).

Urban Health Research Initiative, 2013. Drug situation in Vancouver. 2nd ed. Vancouver, BC: British Columbia Centre for Excellence in HIV/AIDS Available at : https://www.bccsu.ca/wp-content/uploads/2016/08/dsiv2013.pdf [Accessed January 2, 2021]. 